\title{
Correction to: Intergenerational Ethnic Identity Construction and Transmission among Italian-Australians
}

\section{Correction to:}

S. Marino, Intergenerational Ethnic Identity Construction and Transmission among Italian-Australians, https://doi.org/10.1007/978-3-030-48145-2

The following corrections were made in the original version of the book:

1. In Chapter 9, the text See Fig. 9.2 has been deleted.

2. In Chapter 10, the text unrelated to the chapter content which was published has been deleted.

The corrections to the book have been updated with the changes.

The updated versions of these chapters can be found at https://doi. org/10.1007/978-3-030-48145-2_9 and https://doi.org/10.1007/978-3030-48145-2_10

(C) The Author(s) 2020

S. Marino, Intergenerational Ethnic Identity Construction and Transmission among Italian-Australians, https://doi.org/10.1007/978-3-030-48145-2_11 